$$
\text { "szlavi-zsako" — 2004/7/22 — 15:35 — page } 151 \text { — \#1 }
$$

\title{
Delusions in informatics education
}

\author{
PÉTER SZLÁvi and LÁSZló ZsAKó
}

Abstract. In the following article our intention is to try to introduce the negative ideas that exist today in Hungary regarding informatics education within the secondary education system. [Zs] As far as we know, these delusions are characteristic of not only Hungary, but we believe that we should look for our own mistakes, that is why we refer to Hungarian examples.

We have examined the informatic knowledge taught in the first 10 years of secondary education, the possible curriculum of the general informatics subject.

To reach our aim, first we have to deviate a bit from our original topic, because without this, it would be more difficult to understand the core subject of the article. In the deviation we will explain what is called informatics, what is called informatics subject. Then we will deal with the main topic and in the summary we will explain what we believe is the aim of general informatics education.

Key words and phrases: teaching programming, algorithms, programming languages, systematic programming, application programs.

ZDM Subject Classification: B30, B40, C60, D40.

\section{The definition of informatics}

Informatics, as one of the youngest branches of science, field of education is difficult to define. There are many reasons for this. One is that it is relatively young, another is that it is developing very fast and it has effects on many other branches of culture.

Today, informatics and traditional communication are being fused and even ordinary people can feel the effects of this (communication on the internet, mobile

Copyright (C) 2004 by University of Debrecen 


$$
\text { "szlavi-zsako" — 2004/7/22 - 15:35 — page } 152 \text { — \#2 }
$$

communication), and the first signs of the fusion of the media and informatics have already appeared.

Its boundaries are very flexible because of its effects on other branches of culture. It is very difficult to define, for example in connection with inheritance and genetics where biology ends and informatics begins.

Let us see two possible definitions!

Definition 1. Informatics is a branch of science that deals with the origin, transmission, storage and procession of information (that is telecommunication, entertainment electronics, genetics, psychology, technology, etc. are also included in it).

DEFINITION 2. Informatics = a branch of science dealing with the means and general methods of processing information with the help of a computer.

The first definition can be linked to the German- (French-) speaking countries, the second to the English-speaking world. The first definition is apparently more general, the second one is more specific (even if we use the term computer in the widest possible sense, that is including e.g. the mobile phone).

By doing this, we have postponed defining informatics, because we traced it back to the notion of information.

We can try to approach the question from a different point of view. Informatics deals with man-to-man communication in the first place. This is a rather general term, as it includes speaking, writing, mimicking, behaviour, etc. Since writing was introduced, man-to-man communication has been divided into two distinct parts: the sender and the receiver of the information can be at a different place in space and time. The developments in information technology (telecommunication, etc) in the past 50 years have created many new ways for processing the information between the two parties. This also leads us towards a more general and a more specific definition: we can talk about general communication between people, and about communication via intelligent communication devices. [B1], [B2]

In this article our aim is narrower than the general definition of informatics: we would like to define the content of the informatics culture in secondary education. 


$$
\text { "szlavi-zsako" — 2004/7/22 - 15:35 — page } 153 \text { — \#3 }
$$

\section{The delusions of informatics education}

The scope of knowledge of the general informatics subject is widely debated among IT teachers as well, but even more debated among informatics experts and parents lay in informatics. We are trying to highlight the areas to be taught, their importance and proportions in a way that we point out the mistaken, rather extreme views and then discuss them with criticism. [NAT]

Certainly, there is an element of truth in each delusion, but their extreme application is undoubtedly wrong. Students can realise which scopes of knowledge and to what extent they should include in Informatics as a subject during the debates about these delusions.

Let us see the delusions now!

- Informatics subject = informatics according to the general definition

If informatics as a subject is based on the general definition, there is, in fact, no need for other subjects at school, as mathematics is about processing information as well, biology is full of genetic information, grammar is about language information, etc. $[\mathrm{F}]$

It is not only the fact that there is no IT teacher that can teach each field at a high level, but it is the fact that we must not cram so many subject matters into one subject ${ }^{1}$.

Each subject must contain a curriculum, which is well-defined, distinctly separated from the curricula of other subjects, yet it must be closely related to the others.

It must examine the world from one aspect, with a unified method so that students of different age groups could all comprehend it.

The general definition of informatics is too wide for this, it would require an enormous number of lessons to teach it properly; in a narrower sense, however, the subject would become superficial, meaningless, boring.

The divergences between the two definitions can easily be reconciled: the second - narrower - definition is about informatics as a subject, and the first - wider - definition is about the fact that the devices and methods of informatics should be used by other subjects as well.

\footnotetext{
${ }^{1}$ Technology as a subject attempted to do this in the 1980's and 1990' and as a result it failed ignominiously.
} 


$$
\text { "szlavi-zsako" — 2004/7/22 — 15:35 — page } 154 \text { — \#4 }
$$

\section{- Informatics education $=$ professional training}

The supporters of this delusion also say that there is nothing in informatics that belongs to general culture; there is no need for a new type of computer literacy; there is no need for a new problem solving culture; ... which means that informatics is a privilege for only a few people. It leads us to the conclusion that there is need for neither informatics as a subject nor IT teachers in secondary education.

This aspect is fundamentally mistaken, the last time people could hold this view was back in the 1970's, but it was destroyed by the introduction of personal computers in the 1980's, while the information society of today is about the fact that informatics is for everyone.

On the basis of this delusion some anti-delusions also appeared as listed below, and as a result, certain elements of the curriculum used in professional informatics training began to be used in general education as well, which was completely unnecessary.

We can conclude that within the notion of informatics, general informatics and - the many types of - professional informatics training should be separated. Both are needed and the structure of each should be defined by its own logic and needs.

\section{- Informatics education = teaching users only}

According to this, informatics is about being able to use computers (and other devices) properly. This delusion holds that the development of abilities, the improvement of problem solving skills, the practice of problem solving activities and the ability to invent are not part of informatics ${ }^{2}$.

This delusion was created as an opposite to the following delusion (informatics education $=$ teaching programming), and it took nearly 10 years to fight it. It is interesting to note that people who fought against this idea were the ones who had earlier fought against the opposite delusion as well.

The supporters of this delusion often say that it is unnecessary to teach programming because only a few students will become programmers. This is nonsense, and can only be accepted by the blind. Some of the questions that illustrate this are as follows: Why do we teach mathematics: do we want everybody to become a mathematician? If only a small number of students becomes a historian, why to teach history?

\footnotetext{
${ }^{2}$ Even the caveman used his invention skills to rise above animals.
} 


$$
\text { "szlavi-zsako" — 2004/7/22 - 15:35 - page } 155-\# 5
$$

Mathematics is taught because it improves thinking and other abilities, and the role of informatics is very similar to this ${ }^{3}$. Our world is full of algorithms, we always do algorithms in our everyday life, daily work, while studying. Therefore it is in our own interest to improve our knowledge to understand, execute, even to design algorithms.

\section{- Teaching users = knowledge of the functions of the application pro-} gram $^{4}$

This delusion implies that mainly those who are especially good at handling the different means of informatics, know the menu lists, icons and function keys, etc. well, can use them properly.

This view has two main mistakes. One is that users can acquire knowledge of a high level not because of their technical knowledge but on the basis of their understanding of the general principles, methods. For example, it is not the menu of the word processor that one should know but the form of a letter, an article on the one hand, and the terms (character, word, line, paragraph, etc.) and functions (formatting characters and paragraphs, spell check, etc.) to be used while composing a text document, on the other.

Secondly, hardware knowledge becomes out-of-date every year because of the rapid development of informatics, thus we often have to get acquainted with new hardware, while the general principles remain - basicly - unchanged.

To sum up, we can say that long lasting knowledge is essential but to be able to understand and practise them we need the hardware knowledge that soon becomes out-of-date.

\section{- Informatics education = teaching programming only}

This is the opposite of the previous delusion and it claims everything that is denied by the former. Namely, there is no need for a new form of computer literacy, informatics does not change our everyday life, or at least not in a way that should be taught systematically.

They set the following examples: we are not taught to use the telephone or the television at school, and this aspect is true for all the applications of informatics. Even the starting point of this statement is false: most people use their mobile phones (even the remote control of their tv set) in a primitive,

\footnotetext{
${ }^{3}$ For mathematics education it is worth considering the following statement: programming can be an experimental device for mathematics! Nevertheless, pedagogy considers experimentation extremely useful in the process of recognition.

${ }^{4}$ It is a 'sub-delusion' of the previous delusion.
} 
very limited way. Informatics invades our everyday life, our simple devices become complex, multi-functional, with a number of possibilities. It is a wellknown fact (both in pedagogy and in programming) that beyond a certain extent of complexity, frontal recognition, problem solving techniques become difficult, the process of acquisition slows down and it requires such an extent of abstraction skills and notion recognition to understand the logic of the system that can be developed much slower alone than in a well-constructed learning process.

This delusion appeared when computers could only be used for programming, which was characteristic of the 80 's after the introduction of personal computers that could be programmed in BAsIC language only. Later, when application systems became widespread this delusion was pushed into the background and nowadays it is supported by mainly informatics experts working in the secondary education system, whose job is to distribute programming tasks.

To be able to avoid the two extreme delusions (teaching only users, teaching only programmers) the best course of action to do (like Gyula Kabos, the famous Hungarian actor once said) is: to take a little bit of this and a little bit of that as well.

\section{- Teaching programming = teaching one programming language}

This sub-delusion is very similar to the one which believes that teaching users means teaching application system management.

Teaching programming (or rather teaching algorithmization and data modeling) is based on general principles, which remain unchanged through time (although they are improved), while the programming language is the tool that we need to realise, try, etc. our algorithms on the computer. Programming languages, their set of devices develop at such a speed that it is completely different from what it was 10 years ago, it was different 10 years ago from what it had been 20 years ago and so on. However, they all needed problem solving ability.

- Informatics education = teaching independent scopes of knowledge one after the other

This delusion claims that each part of informatics should be taught linearly, one after the other (like history ${ }^{5}$ ). There is a curriculum for 6 -year-long

${ }^{5}$ We doubt whether it is a good idea to teach ancient history in the 5 th year and the Middle Ages in the 6th. 


$$
\text { "szlavi-zsako" — 2004/7/22 - 15:35 — page } 157 \text { — \# }
$$

secondary schools, in which informatics education is divided into the following steps:

1st year: structure of the computer, hardware knowledge

2nd year: operation systems, general software knowledge

3rd year: word processing

4th year: spreadsheet outlining

5th year: programming

6th year: database management

People who teach students like this say that a 12-year-old child is able to understand everything that is included in the hardware knowledge in secondary education, he is interested in it and is motivated to study. On the other hand, algorithmization and database management should only be taught towards the end of secondary education, as there is no need to understand the algorithm of crossing the street, they do not need to find a train in the railway timetable database, or look for a film in the cinema programme, etc.

It makes no sense this way. Each part of informatics contains information that is most useful at nursery school, others are best taught at the end of secondary school only, or even at university ${ }^{6}$.

- Informatics education = teaching scopes of knowledge of the same value

This delusion can be seen in the curriculum for 6-year-long secondary schools mentioned above. It is based on the absurd idea that each subject can be divided into parts of the same size, which are different in their contents ${ }^{7}$.

Informatics, just like other subjects, has parts of different value. It is obviously not necessary to teach as much hardware knowledge as much algorithmization or application knowledge. However, students need more hardware knowledge than computer science history.

This and the previous delusions led to the dreadful curriculum above, which can only be used for making students hate informatics.

The good informatics curriculum pays attention to the relationship between the students' abilities and their interests and determines what and

${ }^{6}$ Nobody would dare to teach reading in the 1 st year, writing in the $2 \mathrm{nd}$ and spelling in the $3 \mathrm{rd}$ within the frame of Hungarian language and literature.

${ }^{7}$ It is interesting to note that the same problem is not discussed in the classical subjects, nobody wants to spend the same amount of time on geometry and on the theory of probability when teaching mathematics, etc. 


$$
\text { "szlavi-zsako" — 2004/7/22 - 15:35 — page } 158 \text { — \#8 }
$$

when to teach what and when it is needed. A subject is easy to teach when students need the information included, they can apply it ${ }^{8}$ at once and when they have the necessary abstraction skills to be able to understand the subject.

- Informatics education = teaching some arbitrarily chosen parts of informatics

This is the semi-educated IT teachers' delusion, who does not know or like certain parts of informatics, that is why they do not teach them.

Each part of informatics has its own aim and thus the reason why it is included in the curriculum. Omitting something will leave students' knowledge one-sided.

Note: This delusion has nothing to do with the important principle that students of different interests should be taught different parts of informatics with different emphasis: a class specialised in mathematics needs more programming, a class specialised in classics needs more word processing, while for an arts class graphics and multimedia are more important, etc. A good curriculum offers a large scope for informatics diversity.

- Informatics education = studying one informatics device completely

In its original form it meant that all the instructions of one programming language, all the orders (today it would mean the menu lists, icons, sub-programs) of one operation system should be taught. After application systems became widespread other points were also included: the complete menu list of a word processor, all the functions of the spreadsheet outlining, etc. should be taught.

Glancing around at jobs that are linked to informatics we can see that an editor does not use most of the functions of a word processor/editing program, or even experienced computer users do not use all the orders of the operation system (I dare say that most of them have used only about half of the orders so far in their work). The newest operation systems (and application systems as well) are loaded with possibilities and sub-programs which are not used by an everyday user, but they have been made because of marketing concepts (in case anyone may ever need them).

${ }^{8}$ Another pedagogical truth is as follows: the ultimate form of understanding is when we can apply what we have learnt in a creative way. 


$$
\text { "szlavi-zsako" — 2004/7/22 — 15:35 — page } 159 \text { — \#9 }
$$

To sum up: if a professional never uses most of the functions of these systems, it would be a sin to include them in general informatics.

\section{- We should always teach the newest device}

It is often required by the parents, sometimes by the maintainer of the school. It is based on the fact that work places usually use newer software versions than most of the schools.

This view is wrong for many reasons. There is a financial one: it is in the software manufacturers' interest to release a new version yearly or every second year, for which they earn good money. Most schools, however, cannot afford to buy them.

As a school should use about 15-20 software devices, it would also mean that an IT teacher should try, get acquainted with, examine the possibilities and the possible errors (unfortunately there are numerous) of so many new devices every year. For this their number of lessons taught should be reduced by half.

There is a more serious reason as well: the new features of the new versions usually fall within the scope of the previous delusion, that is they contain possibilities that an everyday user does not need and will never rely on.

Consequence: A school has to change a software device when students can improve their general knowledge with the help of the new versions.

\section{- Informatics education = university in small}

This is a dead end where newly graduated teachers get lost. University training is the same for all students teaching either secondary informatics, in professional training or in adult education. A reduced version of the university course is specifically harmful in secondary education (and in the other two fields as well). That is why it is dangerous when graduated teachers rely on the university course as a sample, instead of dealing with the methodology of setting up a curriculum properly.

\section{- The IT teacher knows less than the student}

It is often argued that a talented, 'fanatic' student knows more than his teacher. The reason for this is that they can spend long nights and days in front of the computer.

Most of their knowledge, however, is based on system related knowledge, which rapidly becomes out-of-date. It is easy to gain lexical knowledge, experience in usage, learn the ins and outs by being a fanatic. However students 
will never be able to compete with their teachers regarding general knowledge, abstraction skills, comprehension skills, realizing usefulness because of their age.

\section{- Informatics education does not require informatics as a subject}

This aspect is claimed by leading informatics and education experts. Some of the opinions made in secondary are as follows:

- Although I did not study informatics at school, I have become a leading expert.

- I did not study informatics and I do not use the information given in books on informatics today, either.

On one hand this view is based on the fact that the school system does not change and claims that schools do not have to adapt to the changes of the world. On the other hand, it refers back to the delusion about professional training: the question of what and when to study to become a professional belongs to the sphere of professional training and it has little to do with secondary informatics.

If informatics is divided into subjects, it is doubted whether there will be an integrated approach, whether the parts will be based on each other and the interests of other subjects can even overshadow the relevant informatics knowledge, or certain areas could be excluded.

To teach an area of culture within a separate subject is justified if it contains a mass of information which is necessary for the development of basic skills, if it helps orientation in the world and makes it easier to understand the different phenomena of the world. The formation of the informatics society makes this subject legitimate and essential.

Certainly, there is an element of truth in each delusion, but their extreme application is undoubtedly wrong. Students can realise which scopes of knowledge and to what extent they should include in Informatics as a subject during the debates about these delusions.

\section{References}

[Zs] László Zsakó, Az informatika ismeretkörei (The Scopes of Knowledge in Informatics), ELTE TTK Informatikai Tanszékcsoport (Informatics Department at The faculty of Science, ELTE,), 2002. 


$$
\text { "szlavi-zsako" — 2004/7/22 — 15:35 — page } 161 \text { — }
$$

[B1] András Benczúr, Informatika - oktatás - informatikaoktatás (Informatics - Education - Informatics Education), Természet világa különszám (The World of Nature, special edition), 2000, 30-37.

[B2] András Benczúr, A kommunikáció fejlödése és az információs forradalom (Evolution of Communication and the IT Revolution), Természet világa (The World of Nature, special edition), 2003, 74-79.

[NAT] Informatika a Nemzeti Alaptantervben (Informatics in the "National Ground Curriculum"), EVilág 2003/10 (eWorld), 2003, 22-25.

[F] János Fercsik, Informatika és számitógép (Informatics and Computers), Müszaki könyvkiadó, Budapest, 1993.

PÉTER SZLÁVI

FACULTY OF INFORMATICS

EÖTVÖS LORÁND UNIVERSITY

BUDAPEST

HUNGARY

E-mail: szlavi@ludens.elte.hu

LÁSZLÓ ZSAKÓ

FACULTY OF INFORMATICS

EÖTVÖS LORÁND UNIVERSITY

BUDAPEST

HUNGARY

E-mail: zsako@ludens.elte.hu

(Received March, 2004) 